\title{
Sub-minimum inhibitory concentration of rifampin: a potential risk factor for resuscitation of Mycobacterium tuberculosis
}

\author{
Shahin Pourazar Dizaji ${ }^{1}$ Alireza Taala ${ }^{1}$, Morteza Masoumi ${ }^{1}$, Nayereh Ebrahimzadeh', Abolfazl Fateh ${ }^{1,2}$, \\ Seyed Davar Siadat ${ }^{1,2}$ and Farzam Vaziri ${ }^{1,2^{*}}$ (D)
}

\begin{abstract}
Background: Mycobacterium tuberculosis possesses five resuscitation-promoting factors, Rpf $A$ to $E$, which are required for the resuscitation of dormancy in mycobacteria. This study explores the transcriptional profile of all five rpfs of $M$. tuberculosis, in response to sub-MIC concentration of rifampin, in multidrug and mono-rifampin resistant clinical isolates.

Methods: Thirteen multidrug and two rifampin mono resistant clinical isolates were analyzed. Drug susceptibility testing and determination of MIC were performed. The relative expression of rpfs was measured, by real-time quantitative PCR.

Results: A significant upregulation of relative expression $(p<0.05)$ was observed, as follows: 7/15(46.66\%); 5/15(33.33\%); $9 /$ 15(60\%); 10/15(66.66\%) and 9/15(60\%) in rpfA, rpfB, rpfC, rpfD and rpfE, respectively.

Conclusion: Our results showed that the rpfs could be overexpressed in some extent in the presence of sub-MIC concentration of rifampin in multidrug and mono drug resistant $M$. tuberculosis. These results highlight the potential risk of sub-MIC rifampin concentrations, as a risk factor for tuberculosis reactivation.
\end{abstract}

Keywords: Mycobacterium tuberculosis, Resuscitation promoting factors, Rifampin, Sub MIC, Transcriptional profile

\section{Background}

Tuberculosis (TB) is a life-threatening bacterial disease, caused by Mycobacterium tuberculosis (M. tuberculosis). This bacterium is a very successful pathogen that can persist in its host, regardless of a strong immune response; and causes latent TB infection (LTBI) [1]. The situation will become more complicated, by the emergence and spread of multidrug-resistant (MDR-TB) and Rifampin mono resistant (RMR-TB) strains of $M$. tuberculosis, which represents a major challenge to the global control of the TB [2-4]. Although the host-pathogen interactions resulting in LTBI remain elusive, the exact mechanism through which $M$. tuberculosis switches from its dormant state to active form, is currently attracting much of the research activity in this field [5].

\footnotetext{
*Correspondence: farzam_vaziri@yahoo.com; f_vaziri@pasteur.ac.ir 'Department of Mycobacteriology and Pulmonary Research, Pasteur Institute of Iran, Tehran, Iran

${ }^{2}$ Microbiology Research Center (MRC), Pasteur Institute of Iran, Tehran, Iran
}

The factors found to be responsible for awakening the dormant bacteria, belong to the so-called Rpf (Resuscitation promoting factors) proteins. This family of proteins in $M$. tuberculosis is composed of Rpf A to E [6]. Rpfs have been proposed to act as peptidoglycan hydrolases, implicated in remodeling of the bacterial cell wall, through cleavage of the beta-1,4-glycosidic bond in peptidoglycan, which help in cell division and/or release of anti-dormancy factors [7]. Experiments with $M$. tuberculosis rpf mutant strains have shown that Rpf proteins determine the ability of such strains to establish the LTBI in animal models and to be resuscitated with the development of an active TB [8].

Expression of different factors in bacteria is regulated by a network of regulatory and signaling pathways that respond to specific environmental cues, such as $\mathrm{pH}$, nutrient status, ions, temperature and most importantly, antibiotics at sub-Minimum Inhibitory Concentration (MIC), which can alter the expression pattern of the genes [9].

In the current study, an attempt has been made to prove this hypothesis that sub-MIC concentration of rifampin 
might be a potential risk factor in the resuscitation of MDR and RMR in M. tuberculosis clinical isolates.

\section{Methods}

Bacterial strains and drug susceptibility testing

Thirteen MDR and two RMR clinical isolates were selected, from M. tuberculosis strains collection of the Department of Mycobacteriology and Pulmonary Research, Pasteur Institute of Iran. M. tuberculosis strains were isolated from patients with pulmonary TB, from January 2010 to March 2015. Ethical reviews and informed written consent approval were granted by the Ethical Committee of the Pasteur Institute of Iran (Tehran, Iran). Informed consent was obtained from all of the patients, enrolled in the study. The isolate profiles of drug susceptibility were re-confirmed by the proportional method, using Lowenstein-Jensen medium, supplemented with Isoniazid (INH), $0.2 \mathrm{mg} / \mathrm{L}$; Rifampin (RIF), $40 \mathrm{mg} / \mathrm{L}$; Streptomycin (STR), $4 \mathrm{mg} / \mathrm{L}$; Ethambutol (EMB), $2 \mathrm{mg} / \mathrm{L}$; Kanamycin (KAN), $30 \mathrm{mg} / \mathrm{L}$ and Ofloxacin (OFX), $2 \mathrm{mg} / \mathrm{L}$ [10]. Bacterial growth on antimicrobial agents-containing media, exceeding $1 \%$ of the number of colonies on antimicrobial agents-free media (control), were considered to be resistant to the antimicrobial agents. All experiments were performed, in accordance with the guidelines, approved by Pasteur Institute International networks.

\section{Determination of MIC}

An Alamar blue assay (Thermoscientific, USA) was carried out, as previously described, to determine the MICs of RIF of the 15 clinical isolates [11]. RIF concentrations were 0.001$256 \mathrm{mg} / \mathrm{L}$. All tests were conducted in duplicate. The MIC was defined as the lowest antibiotic concentration that inhibits any color change. Isolates with MICs of RIF $<1 \mathrm{mg} / \mathrm{L}$ were defined, as being susceptible. For next-step analysis, the bacteria, growing in sub MIC concentration were selected.

\section{RNA extraction and reverse transcription}

All M. tuberculosis strains were sub-cultured in $7 \mathrm{H} 9$ medium, supplemented with Albumin Dextrose Catalase (ADC), in the absence of rifampin (control strains) and presence of sub-MIC of rifampin $(\mathrm{MIC}=128 \mathrm{mg} / \mathrm{L})$, and collected after four weeks for RNA extraction. Total bacterial RNA was isolated, using PREP-NA DNA/RNA extraction kit (DNA technology, Russia). The quality and integrity of the total RNA was assessed, using a nanophotometer (Thermoscientific, USA) and agarose gel electrophoresis. After DNase I treatment, RNA $(1.5 \mu \mathrm{g})$ was reverse transcribed, according to the manufacturer's recommendations (PrimeScript First Strand cDNA Synthesis Kit, Takara, Japan), and the thermal cycling conditions were as follows: $25^{\circ} \mathrm{C}$ for $10 \mathrm{~min}, 42{ }^{\circ} \mathrm{C}$ for $60 \mathrm{~min}$, and $85{ }^{\circ} \mathrm{C}$ for $5 \mathrm{~min}$. The cDNAs were maintained at $-20{ }^{\circ} \mathrm{C}$, until further use.
Quantification of gene expression using real-time quantitative PCR

The primers for $r p f(A-E)$ and $16 S$ rRNA were described, previously [12]. The assay was performed, using a SYBR Premix Ex Taq ${ }^{\text {Tix }}$ II kit (Takara, Japan) in a LightCyler 96 thermocycler (Roche, Germany). Briefly, $10 \mu \mathrm{L}$ qPCR mix, 0.8 pmol each primer, $10 \mathrm{ng} \mathrm{cDNA}$, and RNase-free water were mixed, with a final volume of $20 \mu \mathrm{L}$. The thermal cycling conditions were as follows: $95^{\circ} \mathrm{C}$ for $1 \mathrm{~min}$, then 40 cycles of denaturation at $95{ }^{\circ} \mathrm{C}$ for $10 \mathrm{~s}$, annealing at $55{ }^{\circ} \mathrm{C}$ for $30 \mathrm{~s}$, and extension at $72{ }^{\circ} \mathrm{C}$ for $30 \mathrm{~s}$, and the last step consisted of a melting curve analysis $\left(65-97^{\circ} \mathrm{C}\right)$.

The fold change in the gene expression under rifampin stress in all isolates was calculated by $2^{-\Delta \Delta C T}$ method [13]. 16S rRNA is a housekeeping gene that is expressed at a stable level in the isolates and can be used, as an internal invariant control. For each assay, the results were compared with corresponding M. tuberculosis control growth, in the absence of the rifampin, as the calibrator. Each assay was performed in triplicate, for each gene.

\section{Statistical analysis}

Two-tailed t-test was used for data analysis. All calculations were performed, using SPSS version twenty-two (SPSS Inc., Chicago, IL, USA). Lightcycler 96 software was used for expression data analysis. A $p$ value of $<0.05$ was considered statistically significant.

\section{Results}

Table 1 shows the antimicrobial resistance pattern for all antimicrobial agents used, and the MIC for RIF. Table 2 shows the relative quantification of the transcript levels for the five rpfs in $M$. tuberculosis isolates, exposed to sub-MIC (MIC $=128 \mathrm{mg} / \mathrm{L})$ concentration of RIF.

Significant upregulation of relative expression $(p<0.05)$ was observed as follows: 7/15(46.66\%), 5/15(33.33\%), 9/ $15(60 \%), 10 / 15(66.66 \%)$ and 9/15(60\%) in rpfA, rpfB, rpfC, $r p f D$ and $r p f E$, respectively. Additionally, in three isolates (3/ 15 ; $20 \%)$ one $r p f$; four isolates $(4 / 15 ; 26.66 \%)$ two $r p f$; five isolates $(5 / 15 ; 33.33 \%)$ three $r p f$ and three isolates $(3 / 15$; $20 \%$ ) four $r p f$ were upregulated, simultaneously. None of the isolates had all five-rpf upregulated, simultaneously (Table 2).

\section{Discussion}

TB remains a significant public health problem, globally. The Rpf protein, if appropriately folded, is necessary for both cell wall hydrolysis and reactivation of $M$. tuberculosis [14]. The Rpfs are the secretory proteins, responsible for awaking bacilli from the persistent state, but the exact mechanism of regulation is yet to be determined [15]. Currently, the state of balance between replicating and dormant $M$. tuberculosis, during the course of infection from LTBI to active TB, remains theoretical. In one theory, a few dormant strains (have been termed 'scouts') resuscitate, through signals such 
Table 1 Antimicrobial resistance pattern of six antimicrobials and MIC of RIF

\begin{tabular}{llllllll}
\hline M. tuberculosis strains & INH & RIF & STR & EMB & KAN & OFX & $\begin{array}{l}\text { MIC of RIF } \\
\text { mg/L }\end{array}$ \\
\hline 1 & S & R & S & S & S & S & 256 \\
2 & S & R & S & S & S & S & 256 \\
3 & $\mathrm{R}$ & $\mathrm{R}$ & $\mathrm{R}$ & $\mathrm{R}$ & $\mathrm{S}$ & $\mathrm{S}$ & 256 \\
4 & $\mathrm{R}$ & $\mathrm{R}$ & $\mathrm{R}$ & $\mathrm{S}$ & $\mathrm{S}$ & $\mathrm{S}$ & 256 \\
5 & $\mathrm{R}$ & $\mathrm{R}$ & $\mathrm{R}$ & $\mathrm{S}$ & $\mathrm{S}$ & $\mathrm{S}$ & 256 \\
6 & $\mathrm{R}$ & $\mathrm{R}$ & $\mathrm{S}$ & $\mathrm{S}$ & $\mathrm{S}$ & $\mathrm{R}$ & 256 \\
7 & $\mathrm{R}$ & $\mathrm{R}$ & $\mathrm{R}$ & $\mathrm{R}$ & $\mathrm{S}$ & $\mathrm{R}$ & 256 \\
8 & $\mathrm{R}$ & $\mathrm{R}$ & $\mathrm{S}$ & $\mathrm{R}$ & $\mathrm{S}$ & $\mathrm{S}$ & 256 \\
9 & $\mathrm{R}$ & $\mathrm{R}$ & $\mathrm{R}$ & $\mathrm{R}$ & $\mathrm{R}$ & $\mathrm{S}$ & 256 \\
10 & $\mathrm{R}$ & $\mathrm{R}$ & $\mathrm{R}$ & $\mathrm{R}$ & $\mathrm{R}$ & $\mathrm{S}$ & 256 \\
11 & $\mathrm{R}$ & $\mathrm{R}$ & $\mathrm{R}$ & $\mathrm{R}$ & $\mathrm{S}$ & $\mathrm{R}$ & 256 \\
12 & $\mathrm{R}$ & $\mathrm{R}$ & $\mathrm{R}$ & $\mathrm{R}$ & $\mathrm{R}$ & $\mathrm{R}$ & 256 \\
13 & $\mathrm{R}$ & $\mathrm{R}$ & $\mathrm{R}$ & $\mathrm{R}$ & $\mathrm{R}$ & $\mathrm{S}$ & 256 \\
14 & $\mathrm{R}$ & $\mathrm{R}$ & $\mathrm{R}$ & $\mathrm{R}$ & $\mathrm{R}$ & $\mathrm{S}$ & 256 \\
15 & $\mathrm{R}$ & $\mathrm{R}$ & $\mathrm{R}$ & $\mathrm{R}$ & $\mathrm{S}$ & $\mathrm{R}$ & 256 \\
\hline
\end{tabular}

$R$ Resistant, S Susceptible, INH Isoniazid, RIF Rifampin, STR Streptomycin, EMB Ethambutol, KAN Kanamycin, OFX Ofloxacin

Table 2 Relative expression results of rpf genes under sub MIC of rifampin

\begin{tabular}{|c|c|c|c|c|c|}
\hline M. tuberculosis strains & rpfA & $r p f B$ & $r p f C$ & rpfD & rpfE \\
\hline 1 & $1.073^{*}$ & 0.765 & $1.191^{*}$ & $20.580^{* *}$ & 0.973 \\
\hline 2 & 0.451 & 0.746 & $3.976^{* *}$ & $1.600^{*}$ & 0.838 \\
\hline 3 & $1.249^{*}$ & 0.650 & 0.637 & $1.211^{*}$ & $1.009^{*}$ \\
\hline 4 & $1.165^{*}$ & 0.633 & $1.174^{*}$ & $1.724^{*}$ & $2.575^{* *}$ \\
\hline 5 & 0.493 & $2.644^{* *}$ & $5.275^{* *}$ & $2.854^{* *}$ & $1.356^{*}$ \\
\hline 6 & 0.767 & 0.760 & 0.901 & $1.642^{*}$ & $1.022^{*}$ \\
\hline 7 & 0.567 & 0.956 & $1.361^{*}$ & 0.790 & 0.970 \\
\hline 8 & 0.781 & $1.298^{*}$ & 0.498 & $26.750^{*}$ & $2.017^{* *}$ \\
\hline 9 & $0.410^{*}$ & $13.390^{* *}$ & $6.726^{* *}$ & $1.399^{*}$ & $1.904^{*}$ \\
\hline 10 & $1.309^{*}$ & $1.170^{*}$ & $1.324^{*}$ & 0.641 & 0.771 \\
\hline 11 & - & $0.398^{*}$ & $1.168^{*}$ & 0.752 & 0.932 \\
\hline 12 & 0.727 & $1.087^{*}$ & 0.671 & $1.206^{*}$ & $1.021^{*}$ \\
\hline 13 & $1.458^{*}$ & 0.986 & 0.655 & 0.978 & $1.250^{*}$ \\
\hline 14 & $1.432^{*}$ & $0.385^{*}$ & $1.542^{*}$ & $1.344^{*}$ & $1.198^{*}$ \\
\hline 15 & $1.738^{*}$ & 0.789 & 0.475 & 0.834 & 0.665 \\
\hline
\end{tabular}

Bold ratio: *Statistically significant; $P<0.05$, Relative expression compared with corresponding $M$. tuberculosis control growth in the absence of the rifampin Bold ratio: ** Statistically highly significant; $P<0.001$, Relative expression compared with corresponding $M$. tuberculosis control growth in the absence of the rifampin

-: qPCR failure as Rpfs. In the not well-defined situations, scouts send activation signals (most probably Rpfs) to the majority of the dormant bacteria, causing resuscitation [16, 17]. Understanding the physiology of $M$. tuberculosis during metabolic switching, among active-dormant phases is an interesting area of research.

Reactivation of LTBI is a major problem, in regards to the prevention of the spread of TB. Despite the importance of studying reactivation, limited progress has been made in our understanding of the events, during the transition. One scenario can be the effects of sub-MIC drug exposure on bacterial physiology. Depending on the bacterial species and the classes of antibiotic, these changes lead in either overexpression or downregulation of specific virulence gene, and it is often difficult to identify the exact underlying physiological mechanism, for such alterations [9]. Therefore, in the current study, we investigated the effect of sub-MIC concentration of rifampin on Rpfs expression, in resistant $M$. tuberculosis clinical isolates. It is noteworthy to mention that based on our analysis on $\mathrm{H} 37 \mathrm{Rv}$ (a susceptible reference strain), no changes in the expression level of rpfs were detected (data not shown). This might indicate that very low MIC of RIF for this strain (and of course for other susceptible isolates), cannot affect the $r f p$ expression. Therefore, we have decided to work on MDR and RMR isolates with high MIC. Our results showed that the rpfs could be overexpressed in some extent in the presence of sub-MIC concentration of rifampin in MDR and RMR M. tuberculosis, regardless of their antibiotic resistance pattern.

Some factors increase the risk of TB reactivation, and require screening and treatment for LTBI [18]. Our result highlights the potential risk of sub-MIC rifampin concentrations, as another risk factor in this regard. This issue may be more important in the treatment of LTBI by rifampin monotherapy [19].

Rpf-dependent mycobacteria appear to underlie the difficulty we have, in improving TB treatment, yet their presence appears to be driven, by both treatment and host factors [20]. It is noteworthy to mention that Rpfdependent $M$. tuberculosis bacilli from sputum have been proven to be more tolerant to rifampin [21, 22]. Moreover, $\mathrm{Hu}$ et al. have recently demonstrated that the abundance of these Rpf- dependent $M$. tuberculosis bacilli, correlated with TB reactivation [23]. The correlation between these studies and our results needs further investigation.

Loraine et al. recently showed that Rpf overexpression rescues non-culturable mycobacteria, generated by treatment with first-line antimicrobial agents in vitro. In addition, Loraine et al. proved that the RpfD-overexpressing $M$. smegmatis strains showed consistently higher resuscitation, compared to the other Rpfs [24]. Interestingly, rpfD was the most prevalent (66.66\%) and overexpressed gene in our study (Table 2). Collectively, Rpf overexpression can be a 
potential risk factor for unsuccessful TB treatment. On the other hand, we also observed downregulation (mostly not statistically significant) in the rfps, in response to sub MIC rifampin concentrations. Tufariello et al. showed that the rpfs had decreased expression during reactivation, compared to the chronic phase of TB [25]. However, most of the studies proved that the Rpfs are overexpressed, during resuscitation [26]. Most importantly, $\mathrm{T}$ cell responses may be a signal for bacteria to remain dormant, due to not only proper immune responses but also to the possible destruction of the Rpf proteins. In other words, a debilitated immune system, lead to increase in the Rpfs protein level, which may signal the bacteria to resuscitate [27]. So, overexpression of Rpfs can have similar effects.

Significant progress has been made to understand the biology of Rpfs, illuminating the pivotal role they play, in the TB pathogenesis [20]. According to our results, the sub-MIC rifampin concentrations may have important effects not only on the Rpf expression, but also in the pathogenesis of this ancient scourge (e.g., by upregulation of $r p f s$ ). More investigation is inevitable to prove this hypothesis.

\section{Conclusions}

In conclusion, while the clinical significance of Rpf overexpression awaits further evaluation, our findings indicate that the sub-MIC rifampin concentrations may have important effects on Rpf expression (at least at the transcriptional level), which may result in clinically relevant changes in bacterial behavior. This phenomenon must be investigated in a larger number of strains, using in vivo models in order to elucidate more details about its clinical importance in treatment of TB.

\section{Acknowledgements}

We thank all the personnel of Mycobacteriology and Pulmonary Research Department, Pasteur Institute of Iran for their assistance in this project.

\section{Availability of data and material}

Not applicable.

\section{Funding}

This work was supported by a grant [Number 837] from Pasteur Institute of Iran and a grant [project no. 94009958] by Iran National Science Foundation (INSF). The authors declare that they have no conflict of interest.

\section{Authors' contributions}

SPD and AT performed the research. MM, NE and AF analyzed data. FV wrote the paper. SDS and FV supervised the research. All authors read and approved the final manuscript.

Ethics approval and consent to participate

Not applicable.

\section{Consent for publication}

Not applicable.

\section{Competing interests}

The authors declare that they have no competing interests.

\section{Publisher's Note}

Springer Nature remains neutral with regard to jurisdictional claims in published maps and institutional affiliations.

Received: 28 July 2017 Accepted: 8 November 2017

Published online: 14 November 2017

\section{References}

1. Magombedze G, Dowdy D, Mulder N. Latent tuberculosis: models, Computational Efforts and the Pathogen's Regulatory Mechanisms during Dormancy. Front Bioeng Biotechnol. 2013;1:4. eCollection 2013

2. World Health Organization. 2014. Global tuberculosis report 2014.

3. Martinson NA, Chaisson RE. Survival in XDR TB: shifting the curve and shifting the paradigm. J Acquir Immune Defic Syndr. 2011;57(2):89-91. doi:10.1097/QAl.0b013e31821b4b42.

4. Dramowski A, Morsheimer MM, Jordaan AM, Victor TC, Donald PR, Schaaf HS. Rifampicin-monoresistant Mycobacterium tuberculosis disease among children in cape town, South Africa. Int J Tuberc Lung Dis. 2012;16(1):76-81. doi:10.5588/ijtld.11.0360.

5. Maione V, Ruggiero A, Russo L, De Simone A, Pedone PV, Malgieri G, Berisio $R$, Isernia C. NMR structure and dynamics of the resuscitation promoting factor RpfC catalytic domain. PLoS One. 2015;10(11):e0142807. doi:10.1371/ journal.pone.0142807.

6. Chauviac FX, Robertson G, Quay DH, Bagnéris C, Dumas C, Henderson B, Ward J, Keep NH, Cohen-Gonsaud M. The RpfC (Rv1884) atomic structure shows high structural conservation within the resuscitation-promoting factor catalytic domain. Acta Crystallogr F Struct Biol Commun. 2014;70(Pt 8):1022-6. doi:10.1107/S2053230X1401317X.

7. Kaprelyants AS, Mukamolova GV, Ruggiero A, Makarov VA, Demina GR, Shleeva MO, Potapov VD, Shramko PA. Resuscitation-promoting factors (Rpf): in search of inhibitors. Protein Pept Lett. 2012;19(10):1026-34.

8. Nikitushkin VD, Demina GR, Kaprelyants AS. Rpf proteins are the factors of reactivation of the dormant forms of Actinobacteria. Biochemistry (Mosc). 2016;81(13):1719-34. doi:10.1134/50006297916130095.

9. Andersson DI, Hughes D. Microbiological effects of sublethal levels of antibiotics. Nat Rev Microbiol. 2014;12(7):465-78. doi:10.1038/nrmicro3270.

10. Canetti G, Froman S, Grosset J, Hauduroy P, Langerova M, Mahler HT, Meissner G, Mitchison DA, Sula L. Mycobacteria: laboratory methods for testing drug sensitivity and resistance. Bull World Health Organ. 1963;29:565-78.

11. Palomino JC, Martin A, Camacho M, Guerra H, Swings J, Portaels F. Resazurin microtiter assay plate: simple and inexpensive method for detection of drug resistance in Mycobacterium tuberculosis. Antimicrob Agents Chemother. 2002;46(8):2720-2.

12. Gupta RK, Srivastava BS, Srivastava R. Comparative expression analysis of rpflike genes of Mycobacterium tuberculosis H37Rv under different physiological stress and growth conditions. Microbiology. 2010;156(Pt 9): 2714-22. https://doi.org/10.1099/mic.0.037622-0.

13. Livak KJ, Schmittgen TD. Analysis of relative gene expression data using real-time quantitative PCR and the 2(-Delta Delta C(T)) method. Methods. 2001;25(4):402-8.

14. Zhao S, Song X, Zhao Y, Qiu Y, Mao F, Zhang C, Bai B, Zhang H, Wu S, Shi C. Protective and therapeutic effects of the resuscitation-promoting factor domain and its mutants against Mycobacterium tuberculosis in mice. Pathog Dis. 2015;73(3):pii: ftu025. doi:10.1093/femspd/ftu025.

15. Gupta RK, Srivastava R. Resuscitation promoting factors: a family of microbial proteins in survival and resuscitation of dormant mycobacteria. Indian J Microbiol. 2012;52(2):114-21. doi:10.1007/s12088-011-0202-6.

16. Chao MC, Rubin EJ. Letting sleeping dos lie: does dormancy play a role in tuberculosis? Annu Rev Microbiol. 2010;64:293-311. doi:10.1146/annurev. micro.112408.134043.

17. Epstein SS. Microbial awakenings. Nature. 2009;457(7233):1083. doi:10.1038/ 4571083a.

18. Ai JW, Ruan QL, Liu QH, Zhang WH. Updates on the risk factors for latent tuberculosis reactivation and their managements. Emerg Microbes Infect. 2016:5:e10. doi:10.1038/emi.2016.10.

19. Esmail H, Barry CE 3rd, Wilkinson RJ. Understanding latent tuberculosis: the key to improved diagnostic and novel treatment strategies. Drug Discov Today 2012;17(9-10):514-521. doi: 10.1016/j.drudis.2011.12.013.

20. Rosser A, Stover C, Pareek M, Mukamolova GV. Resuscitation-promoting factors are important determinants of the pathophysiology in 
Mycobacterium tuberculosis infection. Crit Rev Microbiol. 2017:1-10. doi:10. 1080/1040841X.2017.1283485.

21. Mukamolova GV, Turapov O, Malkin J, Woltmann G, Barer MR. Resuscitationpromoting factors reveal an occult population of tubercle bacilli in sputum. Am J Respir Crit Care Med. 2010;181(2):174-80. doi:10.1164/rccm.20090506610C.

22. Turapov O, O'Connor BD, Sarybaeva AA, Williams C, Patel H, Kadyrov AS, Sarybaev AS, Woltmann G, Barer MR, Mukamolova GV. Phenotypically adapted Mycobacterium tuberculosis populations from sputum are tolerant to first-line drugs. Antimicrob Agents Chemother. 2016;60(4):2476-83. doi:10.1128/AAC.01380-15

23. Hu Y, Liu A, Ortega-Muro F, Alameda-Martin L, Mitchison D, Coates A. Highdose rifampicin kills persisters, shortens treatment duration, and reduces relapse rate in vitro and in vivo. Front Microbiol. 2015;6:641. doi:10.3389/ fmicb.2015.00641.

24. Loraine J, Pu F, Turapov O, Mukamolova GV. Development of an in vitro assay for detection of drug-induced resuscitation-promoting-factordependent mycobacteria. Antimicrob Agents Chemother. 2016;60(10):622733. doi:10.1128/AAC.00518-16.

25. Tufariello JM, Mi K, Xu J, Manabe YC, Kesavan AK, Drumm J, Tanaka K, Jacobs WR Jr, Chan J. Deletion of the Mycobacterium tuberculosis resuscitation-promoting factor Rv1009 gene results in delayed reactivation from chronic tuberculosis. Infect Immun 2006;74(5):2985-2995.

26. Kapoor N, Pawar S, Sirakova TD, Deb C, Warren WL, Kolattukudy PE. Human granuloma in vitro model, for TB dormancy and resuscitation. PLoS One. 2013;8(1):e53657. doi:10.1371/journal.pone.0053657.

27. Veatch AV, Kaushal D. Opening Pandora's Box: Mechanisms of Mycobacterium tuberculosis resuscitation. Trends Microbiol 2017 pii: S0966842X (17)30191-30199 doi:10.1016/jtim201708.001.

Submit your next manuscript to BioMed Central and we will help you at every step:

- We accept pre-submission inquiries

- Our selector tool helps you to find the most relevant journal

- We provide round the clock customer support

- Convenient online submission

- Thorough peer review

- Inclusion in PubMed and all major indexing services

- Maximum visibility for your research

Submit your manuscript at www.biomedcentral.com/submit
Biomed Central 